\title{
Analysis of castel type biomass combustion chamber using candlenut shell fuel for patchouli oil purifying
}

\author{
Eswanto $^{1 *}$, and J.R.Siahaan ${ }^{1}$ \\ ${ }^{1}$ Departement of Mechanical Engineering, Faculty of Industrial Technology \\ Institut Teknologi Medan (ITM), Medan-20217, Indonesia \\ *Email: eswanto@itm.ac.id \\ Phone: +0617363771; Fax: +0617347954
}

\begin{abstract}
The combustion chamber is one of the tools used to cultivate plantation, with fuel predetermined. Most people in rural areas the largest users of fossil fuels derived from kerosene, gasoline, petrol, LPG gas, coal and firewood. One agricultural wastes that can be utilized the candlenut shells capable of generating heat energy can help problems of crisis fossil fuel. Biomass fuel type castel space is one of main tools that can convert biomass into thermal energy can be harnessed to the needs of everyday people like cooking. The objective of this research is to know the energy of calor and fuel consumption that produced in combustion chamber of castel type biomass using fuel to hazelnut shell for patchouli oil distillation. This experimental method was conducted experimentally, with the main materials and equipment of combustion chamber biomass type, boiler, boiler water pipe, condenser, centrifugal blower, hazelnut shell, patchouli leaf. The working procedure is started from the combustion process inside the combustion chamber to heat the water in the boiler until distillation process to occur between dried patchouli leaves with water vapor. Then it is cooled from the coil type separator so that the vapor mixture turns phase to water mixture with patchouli oil, then the mixture is separated in the oil phase separator glass by water so that it is obtained pure patchouli oil. The results show that the combustion chamber type that is made have been in accordance with existing theoretical standards. Where the results of testing and data analysis recommend the feasibility to be applied to the patchouli oil industry. In the candlenut shell fuel of obtained heat energy of $\mathrm{Q}_{\mathrm{f}}=9.356 .59 \mathrm{k} . \mathrm{cal} / \mathrm{hr}$ with a temperature of $795{ }^{\circ} \mathrm{C}$, while the higher heating value of $18.446 \mathrm{~kJ} / \mathrm{kg}$ and lower heating value at $17.170 \mathrm{~kJ} / \mathrm{kg}$. The conclusion of this research is that besides can get good distillation technology, also can utilize existing fuel around the residence and not yet utilized in this case biomass of candlenut shell which have high calorific value for burning process in the combustion chamber.
\end{abstract}

Keywords: combustion chamber; candlenut shell; fuelbiomass; oil purifying.

\section{INTRODUCTION}

Currently the fuel derived from biomass becomes a very necessary thing in meeting the energy needs, be it small or large scale. The existence biomass itself helpful in the community because material that allows many places in the vicinity of the dwelling, but in still more complete [1], with varying biomass for materials suitable for the user's need and an alternative material fuel as energy needs [2], which can help the government in 
searching for energy sources with combustion chamber [3-5]. Associated with the current biomass has been started by several countries whereforcing the use of biomass as a renewable energy source is the current global trends. However, it should be not that the massive and uncontrolled use of this fuel, especially in urban areas, could cause negative effects, including those in terms of NOx emissions [6].

In its current development of fuel derived from biomass has become the most important energy source of every region of the world [7, 8]. In addition, biomass has the potential to become one alternative energy sources and the main part of the future combustion system, and the development of science demand the development bioenergy system that can eventually become an important contributor to future sustainable energy development, sustainable in industrialized countries as well as in countries seeking new alternative energy sources [9-12]. We find that it is likely that the cost of fossil fuel power generation will respond to the large scale penetration of renewables, thus making the renewable energy transition slower or more costly than anticipated [13-15].

On the other hand with this difficult economic conditions currently costs needed to get increasingly expensive fossil fuels. Surging crude oil prices in the international market reached US \$ 40.45/barrel (New York Mercantile Exchange, August 2015), has been troubling the world community, particularly the oil importing countries. While the need for fossil fuels nationally to tend increase, this condition not in following with exploration discovery of new oil sources. Through Indonesian Presidential Regulation No. 5 of 2006, the government issued national policy on energy saving and development of alternative energy to reduce dependence on fossil fuels, where we know that the fuel now increasingly scarce and contains excessive emissions, so new ways are needed to meet the need for that energy source [16-18]. Basically, in addressing problem of the need for a shortage energy sources from fossil, while the need for sustainable living continues to increase, efforts are required to utilize various alternative sources. One of them is through the utilization of the remaining agricultural products, plantations or the remaining forest products in the form of biomass, especially from hazelnuts which is still abundant in rural areas so that biomass is the reference from human needs [19].

Seeing the above conditions, it is necessary alternative fuel is cheap and abundant presence in the community. One renewable energy has great potential for Indonesia is the biomass. In thepolicy renewable energy development and energy conservation ministry of energy and mineral resources explained that the definition of biomass energy include wood, agricultural waste, farm waste, forest waste, the organic component of industrial and household. In the development of this biomass if developed in a structured course will have a very big impact, both for the state and society that receive the results of the technology developed. Therefore, in theory, should be applied certain rules for processing potential sources of this biomass [20]. Analytical characterisation of hazelnut samples of the literature is usually focused eitheron the lignocellulosic or the lipid fractions. Plantation wastes biomass that can be processed and used as an alternative fuel one of which candlenut shells. It aims to reduce the use of petroleum fuel, so that problem can be global energy crisis is resolved.In tropical countries like Indonesia and Malaysia is the place to grow candlenut trees, this if not utilized properlywill was very detrimental to the country, because it can be a waste of plantation.In the present work, hazelnut shell and cuticle have been studied with Py-GC/MS using in-situ derivatization with hexamethyldisilazane (HMDS). Pyrolytic profiles have been used to perform semiquantitative calculations. Using relative integrated areas, an estimation of the holocellulose-to-lignin ratio (H/L) was obtained for the two fractions [21, 22]. 
The main concern relevant to use of biomass energy resources is that the energy density of biomass is typicallylower than that of fossil fuels such as coals and the calorific value of biomass is closely affected from moisturecontent that it may reach very high levels especially in case of green biomass and waste materials.Average calorific value of candlenut shells of $21.960 \mathrm{~kJ} / \mathrm{kg}$ and an average ash content of $7.0 \%$ [23]. This proves the use of candlenut shells as fuel is able to increase the efficiency of the calorific value. On the other hand, there still exist extra unknown factors that influence the higher heating value (HHV) of biomass and such factors add more difficulty in modeling of this property [24]. The process of producing biomass fuel is economically with negligible or even positive environmental effects through perennial crops. One of the oldest conversion methods to transform biomass into energy is the combustion due to its versatile character. One of the most important factor the combustion efficiency and energy conversion is the flame temperature [25-30].

Where the draft results did not yet have the air supply optimum fuel, yet has space refueling and in the combustion chamber is also still not utilizing heat energy to the maximum so much wasted heat. Based on the above the author intends to redesign the device repeat room burns at part of room burn, fuel air supply of the blower, and refueling so as to improve the efficiency and performance of the combustion chamber. The results of the previous draft where the stove efficiency $40.66 \%$ when compared to the kerosene stove about $40 \%$ was able to cook 1 liter of water until it reaches $100{ }^{\circ} \mathrm{C}$ in an interval of 22 minutes, while the biomass stove castel type it only takes 3 minutes to heat 1 liter of water to temperature is the $100{ }^{\circ} \mathrm{C}$. With so the authors hope improve the efficiency of biomass fuel combustion chamber castel type [31-32].

The factor that determinesthe usefulness of these biomass is the calorific value. Highercalorific value indicates higher efficiency as an energy source. From the results of research in theSidikalang area Dairi, North Sumatra Province, Indonesia, who already author where people still have the economic and technological lags significantly behindowned facilities and infrastructure is also inadequate in the refining process of patchouli oil revenues. The condition is due to the lack of knowledge about technology, especially in the field patchouli oil refining. So they make distillation of patchouli related research under the title analysis of castel type biomass combustion chamber using candlenut shells fuel for patchouli oil purifying.calorific value of (HHV) is the calorific value obtained from the combustion of $1 \mathrm{~kg}$ fuel, taking into account the vapor condensation heat (water produced from combustion is in liquid form). HHV can be calculated with the Eq (1) below[33]:

$$
\begin{gathered}
H H V=33.950 \mathrm{C}+144.200\left(\mathrm{H}_{2}+\frac{\mathrm{O}_{2}}{8}\right)+9400 \mathrm{~S} \quad(\mathrm{~kJ} / \mathrm{kg}) \\
H H V=9358.59 \mathrm{k} . \mathrm{cal} / \mathrm{hr}
\end{gathered}
$$

where, $C$ is the percent unsure carbon, $H$ is the percent unsure hydrogen, $O$ is the oxygen, $S$ is the percent unsure sulfur. where the condition of the properties that is used to calculate the calorific value of fuel.Lower calorific value (LHV) is the calorific value obtained from the combustion of $1 \mathrm{~kg}$ of fuel regardless of the heat condensation (water resulting from combustion are in the form of gas / steam). LHV can be calculated using the Eq (2):

$$
L H V=H H V-2400\left(M+9 H_{2}\right)(k J / k g)
$$

where, $M$ is the percent unsure moinsture, heat energy is the heat generated by the combustion of fuel in the combustion chamber. Amount of heat energy generated is often 
called the capacity of the combustion chamber, which can be determined by the following Eq (3):

$$
Q_{f}=W_{f} \times L H V \times \eta_{f} \quad(k J / h)
$$

Where, $Q_{f}$ is the number of heat energy $(\mathrm{kJ} / \mathrm{hr}), W_{f}$ is the amount of fuel used during the process $(\mathrm{kg} / \mathrm{hr}), \mathrm{LHV}$ is thelower heating value of fuel $(\mathrm{kJ} / \mathrm{kg}), \eta_{f}$ is the combustion efficiency $(0.90 \div 0.97)$. The combustion efficiency can be demonstrated by the performance furnace are stated at PHU (Percent Heat utilized) or SC (specifik consumption) whose value can be determined by testing Water Boiling Test (WBT) This test includes the ripening amount of water (usually expressed one liter of water) pan on the heat and boiling condition, with initial water temperature measurement, temperature rise during the test a final temperature of water (temperature simering, $\pm 90{ }^{\circ} \mathrm{C}$ ), the number of initial water, amount residual water $(1 \mathrm{~kg}$ water produces, $0.1 \mathrm{~kg}$ of water vapor) and fuel consumption following $\mathrm{Eq}(4),[34,35]$ :

$$
\eta_{c c}=\frac{Q_{\text {out }}}{Q_{\text {in }}} \times 100 \%
$$

Where, $\eta_{c c}$ is the effeciency combastion chamber, $Q_{\text {out }}$ is the energy produced, $Q_{\text {in }}$ is the energy provided. With the design and manufacture of tool is expected to develop patchouli oil refining business that already exist and the handling alternative energy utilization of biomass[36-39]. This condition important because patchouli leaves the refining process requires technology can assist people, so patchouli leaves refining activities are not done traditional or human power, so hope it can assist people in their production processesand fuel can utilize the still untapped biomass such as the candlenut shell, where the calorific value can be utilized for biomass burning systems. In addition, in this study selected biomass fuels from hazelnut shells because this material is still widely found among the community but still not utilized properly, but the value of heat and usefulness is very good if managed properly. The pecan shell will become an alternative biomass fuel that is still widely present in the author's residence and has not been used properly because of limited knowledge by the user community.

The objective of this research is to know the energy of calor and fuel consumption that produced in combustion chamber of castel type biomass using fuel to candlenut shell for patchouli oil distillation

\section{METHODS AND MATERIALS}

\section{Exsperimental Methods}

This research method is done by means of the experiment, the testing space Biomass fuel type castel using candlenut shell fuel for patchouli oil refining conducted in the laboratory phenomenon of Basic Engineering, Department of Mechanical Engineering, Faculty of Industrial Technology, Institut Teknologi Medan (ITM). With using the parameters in the test are: Fuel used of candlenut shell, the mass of the fuel used $1 \mathrm{~kg}$, an ambient temperature of $28^{\circ} \mathrm{C}$, the test substances to clean water, the water volume of 22.2 liter, water boiling time beginning 15 minute, the fuel consumption $0,7 \mathrm{~kg}$ initial boiling water, fuel consumption during patchouli oil refining $12 \mathrm{~kg} / \mathrm{hr}$, centrifugal blower $2 \mathrm{inch}$, a round 
of 3000-3600 rpm. Anemometer used to measure air velocity is $18 \mathrm{~m} / \mathrm{s}$, thermocouple $\mathrm{K}$ type, 5 points used to measure the temperature during the refining process, the scale of mass to weigh lot material consumption fuel used, stop-watch to determine the length of the refining process, the old pilot combustion in oil refining patchouli for 5 hours (experimental conditions can be seen in Table 1 and detail specifications of the measurement presented in Table 2).

Table 1. Experiment conditions

\begin{tabular}{lc}
\hline \multicolumn{1}{c}{ Subject } & Specification \\
\hline The outer diameter of the combustion chamber & $30 \mathrm{~cm}$ \\
In diameter of the combustion chamber & $20 \mathrm{~cm}$ \\
High combustion chamber & $40 \mathrm{~cm}$ \\
Size fuel depletion & $1000 \mathrm{~cm}^{3}$ \\
Spacious shelter ash & $16000 \mathrm{~cm}^{3}$ \\
Boiler & 38,86 liter \\
Fuel & candlenut shell \\
Test material & dry sapphire leaf \\
\hline
\end{tabular}

Table 2. Detail specifications of the measurement

\begin{tabular}{|c|c|}
\hline Subject & Specification \\
\hline Centrifugal blower & $\begin{array}{l}\text { Speed of rotation: } 3000-3600 \mathrm{rpm} \\
\text { Watt: } 260 \\
\text { Voltage: } 220 \mathrm{~V} \\
\text { Cycle: } 50 / 60 \\
\text { Ampere: } 1.6 . \mathrm{a}\end{array}$ \\
\hline Temperature controller & - Control voltage (AC): $(50 / 60 \mathrm{~Hz}) 110-220 \mathrm{Vac}$ \\
\hline 5 point, Autonics & - Power consumption: (Maximum) 3 VA \\
\hline $\begin{array}{l}\text { T4WM } \\
\text { Series: }\end{array}$ & $\begin{array}{l}\text { - Analog: } 0-100 \mathrm{mV}, 0-5 \mathrm{~V}, 1-5 \mathrm{~V}, 0-10 \mathrm{~V}, 0-20 \mathrm{~mA} \text {, } \\
\text { 4-20mA }\end{array}$ \\
\hline Thermocouple K Type & 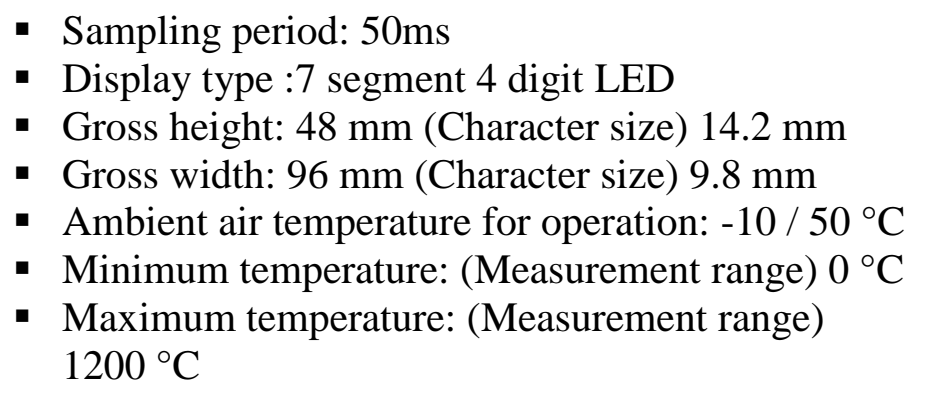 \\
\hline Scales mass & $\begin{array}{l}\text { Capacities: } 2 \mathrm{~kg}-30 \mathrm{~kg} \\
\text { Memory: } 1 \mathrm{~GB} \text { RAM }-1 \mathrm{~GB} \text { Flash } \\
\text { Display: } 7 \text { inch Color Touch Screen } \\
\text { Width } 48 \mathrm{~mm} \text {, Printing Speed Max. } 50 \mathrm{~mm} / \mathrm{second} \\
\text { Power: } 100 \mathrm{~V}-230 \mathrm{~V} \text { Switching Power Supply, } \\
\text { 6V/10Ah Rechargeable Battery as Standard }\end{array}$ \\
\hline Anemometer & Range: $0-30 \mathrm{~m}^{2} / \mathrm{s}$, Resolition: $0.1 \mathrm{~m} / \mathrm{s}$, \\
\hline Model AM-4201 & $\begin{array}{l}\text { Accuracy: } \pm(2 \%+1 \text { d), Max., Min., Data hold, RS- } \\
232 .\end{array}$ \\
\hline Stopwatch Digital & $\begin{array}{l}\text { Up Timer / Stopwatch: } 99 \text { hour, } 59 \text { minute and } 59 \text {, } \\
\text { second + } 1 \text { / } 100 \text { second, Powered by: Button battery } \\
\text { (included), Size (L x W x H): } 8.0 \text { x } 6.4 \text { x } 2.0 \mathrm{~cm}\end{array}$ \\
\hline
\end{tabular}


In this study, using a series of installation the castel type biomass fuesl Candlenutshells fired for patchouli oil purifying, boilers and separators, as shown in Figure 1 along with the measuring instrument. In this study the geometry used to make space of castel type biomass fuel candlenutshells fired for patchouli Oil Purifying is a maximum geometry of each component collected from a variety of different studies. This was done to get the results from the measurement condition the best, so the results can be used by many people both as a reference for researchers and the industry, particularly focusing on the process of distillation and patchouli oil refining. Where we know that the patchouli oil is very much needed in society and expensive if managed properly. Some measurement tools are mounted on this research data collection has been calibrated according to engineering standards, the measurement results can be accounted for righteousness.

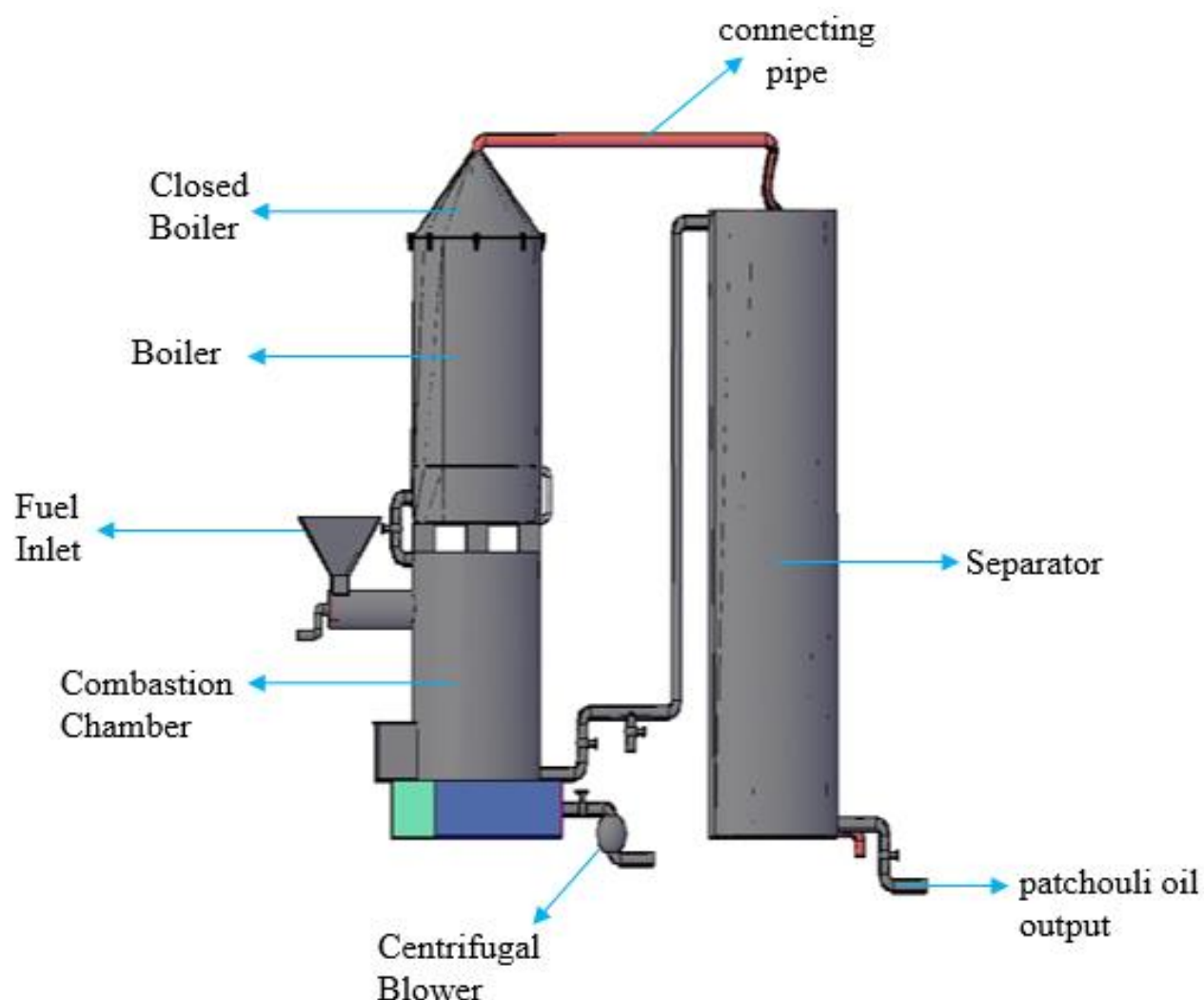

(a)

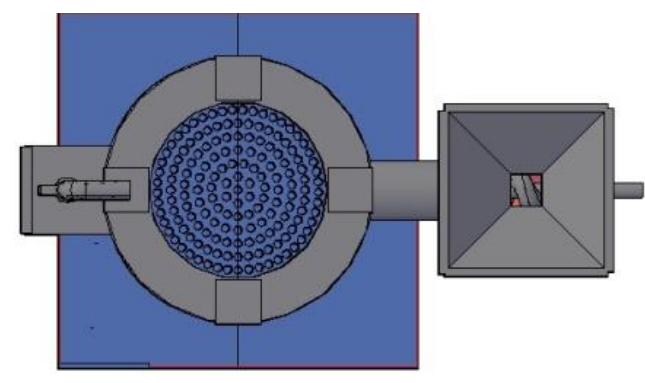

(b)

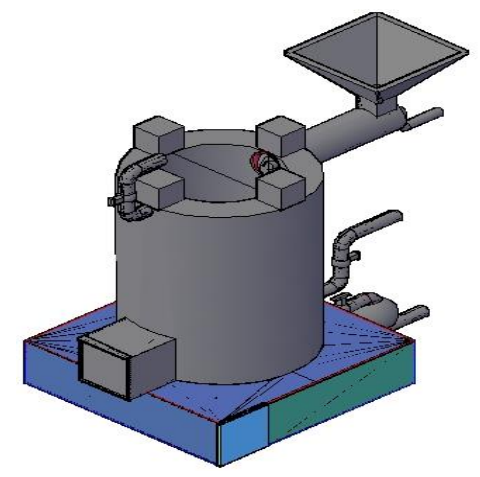

(c)

Figure 1. Experimental setup: (a) installation of testing equipment, (b) close the upper combustion chamber, (c) combustion chamber with screw conveyor. 


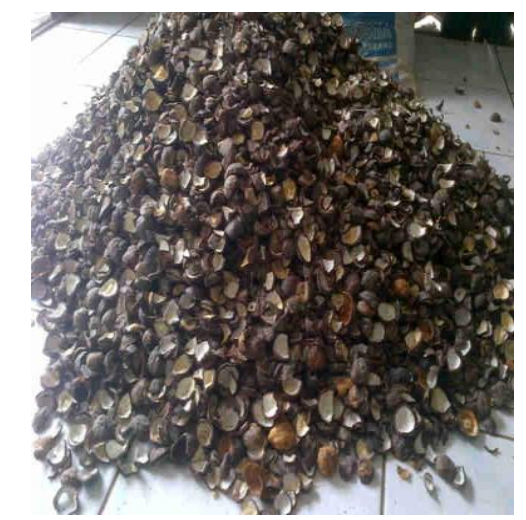

(a)

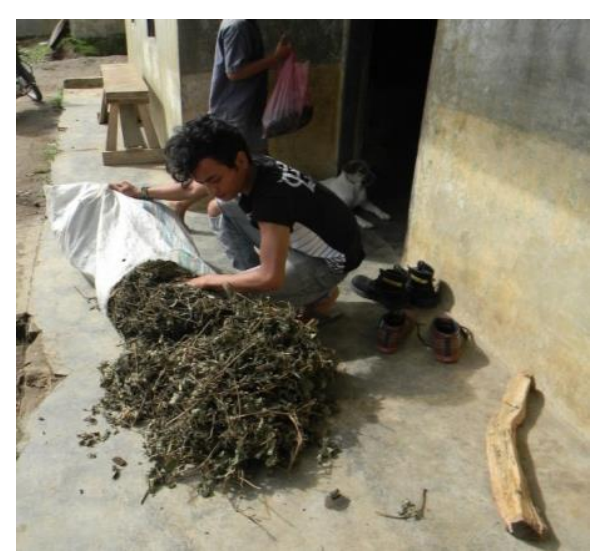

(b)

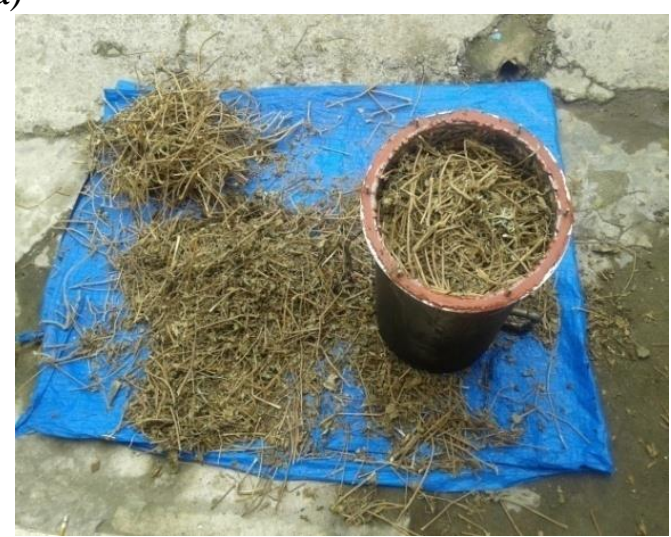

(c)

Figure 2. (a) fuel used is the candle nutshell, (b) patchouli leaves not yet dryand (c) dry sapphire leaf which refined to yield patschouli oil.

Figure 2 shows the candlenut shell and patchouli fuels used in this research. The biomass fuel from the candlenut shell shown in figure (a) is a dried candlenut shell that has been separated with the seeds which are then dried in the sun. At this stage of drying should be done to reduce the water content contained in the nut shell. Selection of dried candlenut shell is very reasonable because it facilitates the burning during the initial startup process in data retrieval in this research process. this condition is very different when compared with the wet hazelnut shell that will slow the initial process of ignition because the shell of candlenut that is not dried in advance there is still water content. Next on the Figure (b) is the material to be tested or done distillation that is patchouli leaves, in Figure (b) is patchouli leaves that are still not dry. In the subsequent process the patchouli leaves which still contain water (Figure b) must be dried first so that it reaches the condition completely dry as shown by the Figure (c) which is dry patchouli which is ready to be tested in the combustion chamber type biomass castel. Dried patchouli leaves that will be tested previously been sorted until clean, it means because the drying process is done on the ground to ensure no other materials such as soil and waste in addition to patchouli leaves into the boiler where patchouli distillation.

The process of collecting data in this experiment conducted by using multiple gauges, which are: thermocouple $\mathrm{K}$ type, 5 points are used to measure the temperature at the time of the combustion process in the boiler refiners patchouli oil, $\mathrm{T}_{1}$ (the temperature of the combustion chamber bottom), $\mathrm{T}_{2}$ (room temperature grilled top), $\mathrm{T}_{3}$ (water temperature in the boiler), $\mathrm{T}_{4}$ (patchouli leaf temperature in the boiler), $\mathrm{T}_{5}$ (steam 
temperature in the pipe).Anemometer used to measure the flow rate of air supplied by blower, stop-watch used to measure the length of time the process of combustion, mass scales used to weigh how much of the mass of fuel used during the combustion process. From experiment castel type biomass combustion chamber using candlenut shells fuel to patchouli oil purifying can be obtained the data in Table 1.

In general, the distillation is the separation of the components of a mixture of two or more types of liquids based on the difference in vapor pressure of each of them. Patchouli oil refining is a process of extracting oil from dried patchouli leaves with the help of water, where oil and water are not mixed. The main parts of the distillers are fire stove, boiler, distiller boiler, condenser or cooler, oil container. The direct steam distillation is principally similar to steam and water distillation, but on direct steam distillation the heat source is present in a steam boiler located separately from the flute kettle, the dried leaves are in the distilled boiler and the water vapor is flowed from the boiler at the bottom of the flute and using higher pressure. The steam distillation system ensures the perfection of patchouli oil production. In this system the material does not direct contact with water or fire.

Procedures and work steps in this research method are to first prepare the raw materials to be in carefully that is dried patchouli leaves, then setup and calibrate the tools that have been prepared previously. Early biomass entry is required for feeding and then put on a burning charcoal, then closed. Blowers that have been switched on the speed of using dimmers in position 4 . Let the initial combustion process lasted for 10 minutes or was not the release of yellowish smoke, after that enter biomass continuous. In principle, the method or process that is carried out when data collection is high pressure steam is flowed from the boiler of water to the kettle containing patchouli leaves which in the process is done with two boilers simultaneously. The water vapor discharged through the pipe that has been installed to the condenser until the condensation process. Then the liquid mixture of water and dripping oil are accommodated with the container provided, then separated to obtain the appropriate pure patchouli oil and good quality.

\section{RESULTS AND DISCUSSION}

In practice the quality and quality of patchouli oil in general is determined by several factors, both of before harvest and after harvest is done. Prior to harvesting factors concerning plant material, cultivation techniques, ways and time of harvest and environmental factors are very influential on the productivity and quality of processed ingredients, which will ultimately affect the quality of processed products or finished goods that are ready to use [40].

The actual fuel air ratio of combustion process is generally estimated at experimental measurement of component in the exhaust gas. There are several ways to analysis experimental compound concentration of gas in gas mixture, among the system is chromatograph orsat gas and equipment. Chromotograph gas is a highly sensitive system that can be used to detect compound that different gases, but this unit is difficult and complicated to use. Orsat otherwise relatively simple equipment and analyzer gas that is compact and portable, which is designed to measure concentration of several gaseous compounds are found in the product of combustion. The test results of this study are presented in the data from the measurement results, which shown in the following Table 3. Data have been obtained from the measurement results is the real result of measurement using measuring instrument that has been installed in accordance with the 
function and desire in getting data distillates patchouli leaves. Temperature data was made into in the 5 point gain consistent measurement remedy as expected.

Table 3. Data testing results combustion chamber castel type

\begin{tabular}{cccccc}
\hline Time(minute) & $\mathrm{T}_{1}\left({ }^{\circ} \mathrm{C}\right)$ & $\mathrm{T}_{2}\left({ }^{\circ} \mathrm{C}\right)$ & $\mathrm{T}_{3}\left({ }^{\circ} \mathrm{C}\right)$ & $\mathrm{T}_{4}\left({ }^{\circ} \mathrm{C}\right)$ & $\mathrm{T}_{5}\left({ }^{\circ} \mathrm{C}\right)$ \\
\hline 0 & 31 & 30 & 28 & 31 & 31 \\
30 & 675 & 530 & 100 & 95 & 45 \\
60 & 680 & 528 & 100 & 98 & 70 \\
90 & 650 & 530 & 100 & 100 & 73 \\
120 & 680 & 535 & 100 & 100 & 75 \\
150 & 700 & 520 & 100 & 100 & 78 \\
180 & 795 & 450 & 100 & 100 & 83 \\
210 & 695 & 530 & 100 & 100 & 90 \\
240 & 750 & 445 & 100 & 100 & 92 \\
270 & 750 & 450 & 100 & 100 & 92 \\
300 & 725 & 470 & 100 & 100 & 95 \\
Average & 710 & 499 & 100 & 99 & 79 \\
\hline
\end{tabular}

The combustion process can be seen during the 300 minute of average temperatureevery point thermocouple during patchouli oilspurifying process, as shown in the Table 4 below. In the combustion process that occurs it is seen the temperature of the burned room using hazelnut shell gives a high value compared to if installed in other parts of the center or in the condenser pipe. This condition is obtained because at the bottom directly exposed to the combustion process in the combustion chamber biomass.

Table. 4. Average temperature and time.

\begin{tabular}{cccccc}
\hline \multirow{2}{*}{ Time (minute) } & \multicolumn{5}{c}{ Average Temperature $\left({ }^{\circ} \mathrm{C}\right)$} \\
\cline { 2 - 6 } & $\mathrm{T}_{1}$ & $\mathrm{~T}_{2}$ & $\mathrm{~T}_{3}$ & $\mathrm{~T}_{4}$ & $\mathrm{~T}_{5}$ \\
\hline 300 & 710 & 499 & 100 & 99 & 79 \\
\hline
\end{tabular}

From data results of testing process that has been acquired over the process into graph that shows the work of combustion during the refining process as shown figure 3 . 


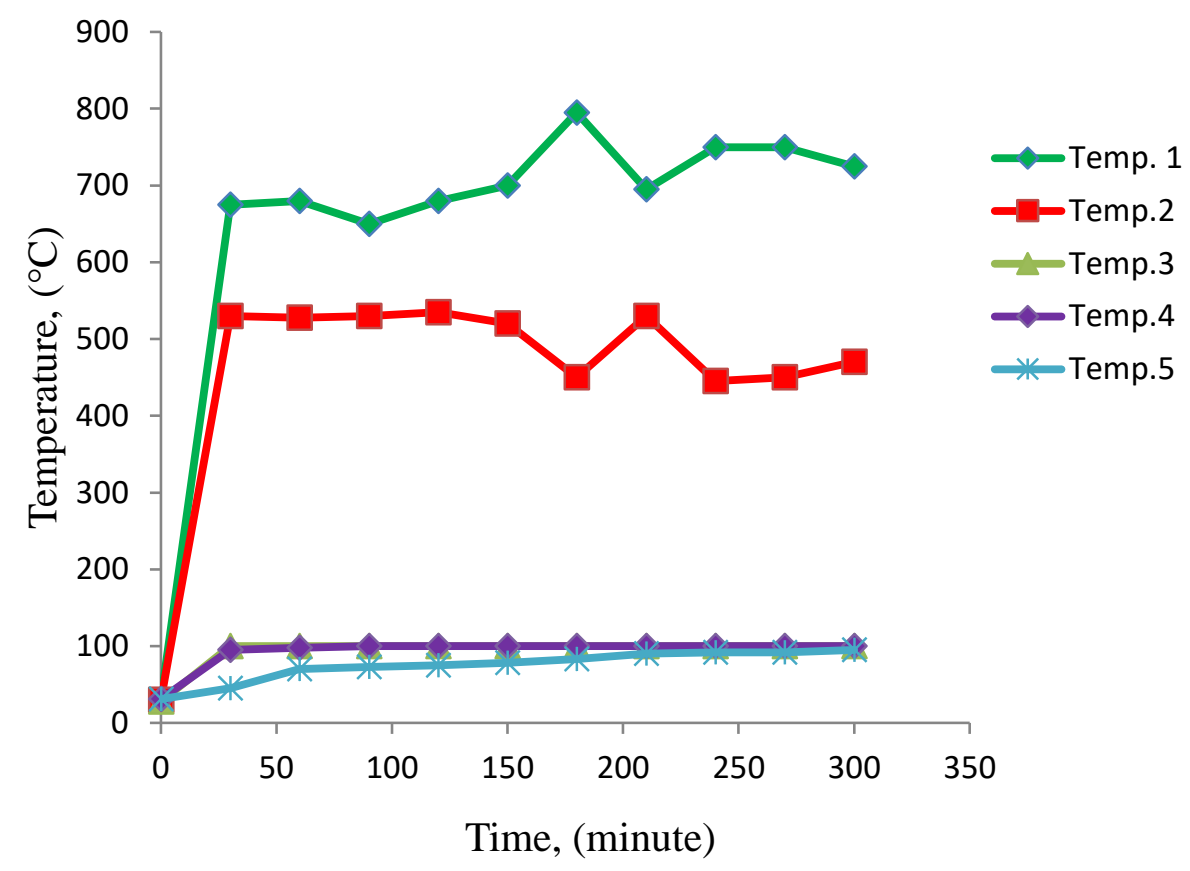

Figure 3. Graph relations time (minute) with temperature $\left({ }^{\circ} \mathrm{C}\right)$.

From the graph of time (minute) Vs Temperature $\left({ }^{\circ} \mathrm{C}\right)$ then temperature earlier in the same thermocouple point at $28{ }^{\circ} \mathrm{C}$, after burning for 30 minute the temperature of each point rise is due to the combustion process in combustion chamber is still not perfect. From the data it appears that at point $\mathrm{T}_{1}=675{ }^{\circ} \mathrm{C}, \mathrm{T}_{2}=530{ }^{\circ} \mathrm{C}$, from 30 to 300 minute temperature rises constantly from the combustion chamber fuel is stable, while the $\mathrm{T}_{3}=$ $100{ }^{\circ} \mathrm{C}, \mathrm{T}_{4}=95{ }^{\circ} \mathrm{C}, \mathrm{T}_{5}=45^{\circ} \mathrm{C}$, an increase in water temperature and vapor due to the heat energy received from fuel combustion process in room burn until constant temperature during the refining process takes place within 300 minute. From figure 3, it can be seen that the lines for temperature $T_{3}$ and $T_{4}$ tend to give the same trend, this condition because of its position lies almost in the adjacent section. In the combustion process of the combustion chamber of biomass with the fuel to this nut shell, where initially the initial process of the occurrence of combustion is supplied by the blower so that air can be pressed on the combustion chamber which will lead to the combustion process. The hazelnut shells that have been prepared and weighed for testing the biomass of the baking room become important because as the main fuel in this process of patchouli oil in producing patchouli oil. From figure 3 , telescence on the line point $T_{1}$ that appears the line of green color on the graph has the highest rise phenomenon, this condition is very reasonable because the placement of the thermocouple measuring instrument is at the bottom of the furnace furnace first directly affected by the combustion process. The same is also expressed by EE Masiren at all, Ali Shiehnejadhesar that there will be a significant rise in temperature if the measuring device is installed in the area closest to the combustion process directly and this condition is different if it is placed farther from the area that was initially exposed to direct contact with the combustion chambers are nearly four times that far from being burnt [41,42] and let alone using fuel from the biomass of the candlenut shell with a high heating value [43].

On the other hand still with the same situation while still reaching 180 minutes $\mathrm{T}_{1}$ temperature has reached 795 and this is higher when compared to when it reaches 300 minutes or the final temperature. This condition allows for further discussion to get the information situation related to the inequality of the phenomenon. However, if further 
analyzed the possibility is caused by the fuel factor that is the biomass of the hazelnut shell that increasingly long in the combustion chamber. If you look carefully at Figure 3, it is likely that other data provide information that the phenomenon is not so strange, this is because the point of placement that is made is not close to the space of the direct occurrence of the combustion process. The results also indicate that the largest average temperature value is obtained in $\mathrm{T}_{1}$ and then up respectively $\mathrm{T}_{2}, \mathrm{~T}_{3}, \mathrm{~T}_{4}$ and $\mathrm{T}_{5}$ respectively, which means combustion process in the combustion chamber type to give a good value of patchouli oil distillation process. The larger the air of the blower is inserted, the resulting flame will decrease further. this condition will inevitably result from the quality of combustion products used in the evaporation process of patchouli leaf distillation and also the temperature will be decreased while the desired are with high temperature but always constant. As related to this temperature has also been obtained by norrizam jaat that the constant the temperature the better the results obtained [44].

From the average data that has been obtained above then processed into a graph showing the average work of combustion during the distillation process as shown in Figure 4 below. If note the installation of the measurement point is done in such a way that the area where will be seen the results of the phenomenon of change. At each temperature change is observed with thermocouple points with time up to 300 minutes. As time goes by testing this data it appears that there is a change from the thermocouple point installed in the bottom of combustion chamber with those along the combustion chamber and condenser. Measurements in this biomass burning chamber are important when they are associated with a temperature change so as to produce the information required in the biomass burning process specifically in the process of patchouli oil refining [45-47].

From the graph of Figure 4, the relationship of thermocouple placement with average temperature indicates the value of $T_{1}$ is the position where the measuring instrument is installed in the combastion chamber. The highest temperature in the measurement combustion process lies in the lower combustion chamber with the magnitude of the average of the recorded temperature is $710^{\circ} \mathrm{C}$. While the average value of temperature at $\mathrm{T}_{2}$ is the measurement lies in the upper combustion chamber of $499{ }^{\circ} \mathrm{C}$. On the other handaverage value of temperature at $\mathrm{T}_{3}$ part of the thermocouple gauge lies water in the boiler of $100^{\circ} \mathrm{C}$, if seen in Figure 4, the object itself is average value of temperature at $\mathrm{T}_{4}$ measurement on the patchouli leaves in boiler for $99^{\circ} \mathrm{C}$. At the last measurement condition of thermocouple can be the average value of temperature at $\mathrm{T}_{5}$ mounted on the vapor in the outlet of $79^{\circ} \mathrm{C}$. 


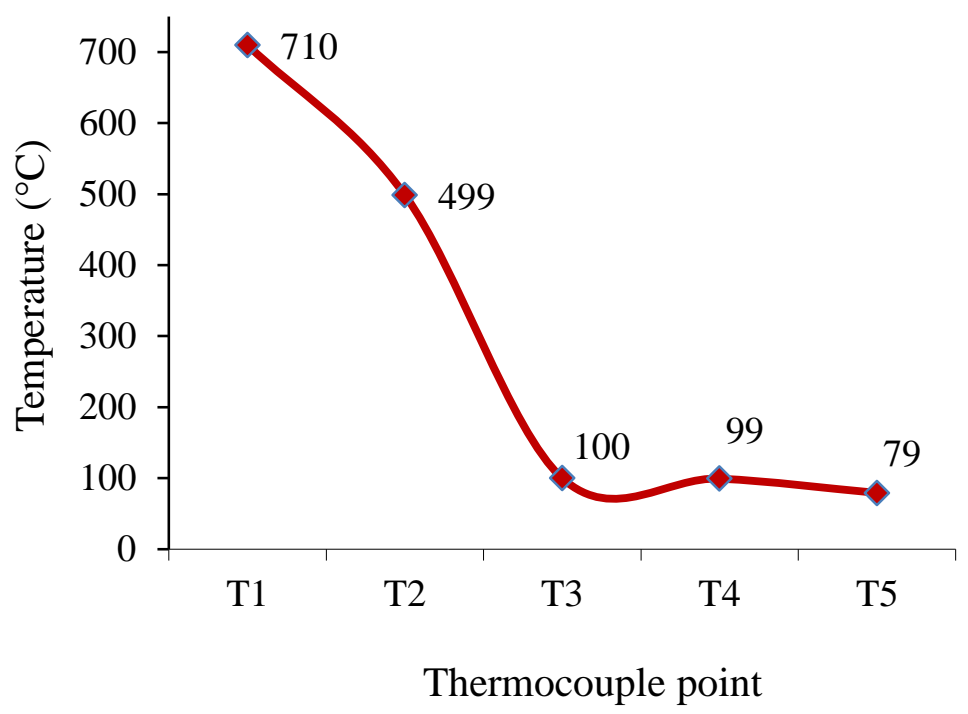

Figure 4. Relationship graph thermocouple point with average temperature.

The high temperature of $T_{1}$ is caused by the positioning of thermocouple sensors located directly at the bottom of the combustion chamber of biomass with the fuel of the hazelnut shells, but also because the calorific value of the hazelnut shell that has met the standard alternative fueling system. Figure 4 also shows the conditions under which the temperature decreases because of the position of the measuring apparatus, with a time of 300 minutes at the point of the thermocouple $\mathrm{T}_{3}$ placed in the center of the distillation furnace there is a decrease in the graph of the Figure 4 shown that after dropping from $499^{\circ} \mathrm{C}$ and then rising at a temperature next. This discussion informs us that the castel combustion chamber provides a true picture of the impact of patchouli leaf distillation into patchouli oil using biomass fuel from hazelnut shells. This type of castel combustion chamber can be used for patchouli refining but must use material that is not too black and recommended from stainless steel material so that the results obtained also better.

\section{CONCLUSIONS}

The energy produced from the combustion chamber of biomass with fuel from the hazelnut shell can be very effective in patchouli oil distillation process. Where the calorific value obtained is $9358.59 \mathrm{k} . c a l / \mathrm{hr}$ which is calculated using the dulog equation. These data are obtained from the thermocouple that have been installed in the test equipment. In the process of distillation of patchouli oil needed biomass fuel from hazelnut shells that is $12 \mathrm{~kg}$ used for 5 hours. The final conclusion is that the methods and tools that can be used in the patchouli refining process can contribute and be applied directly to the farming community in the process, using the fuel and fuel used by the biomass of the hazelnut shell.Hope in the future, in order to be sustainable this patchouli refinery can be made by the community in the process of patchouli oil distillation. This can be done because the process and the material is easily obtained in the market and can be multiplied according to the needs of patchouli oil refining industry. 


\section{ACKNOWLEDGEMENTS}

We thank the Ministry of Research Technology and Higher Education (RISTEK-DIKTI - Republik Indonesia) because these activities are implemented through a research grant No : 116/B3.1/KM/2016 and the Research Team from Mechanical Engineering, Faculty of Industrial Technology, Institut Teknologi Medan, Jl. Gedung Arca No. 52 Medan, North Sumatera - Indonesia.

\section{REFERENCES}

[1] Wielgosinski G,Lechtanska P,Namiecinska O. Emission of some pollutants from biomass combustion in comparison to hard coal combustion. Journal ofthe Energi Institute. 2016;4:1-10.

[2] Li Y, Zhou LW, Wang RZ. Urban biomass and methods of estimating municipal biomass resources. Renewable and Sustainable Energy Reviews. 2017;80:10171030.

[3] Noor MM, Andrew PW, Talal Y. Design and development of mild combustion burner. Journal of Mechanical Engineering and Sciences (JMES). 2013;5:662676.

[4] Schulzke T, Westermeyer J, Giani H, Hornsby C. Combustion of refined renewable biomass fuel (RRBF) in a bubbling fluidized bed. Renewable Energy An International Journal. 2017;(9):1-11.

[5] Jing W, Wu Z, Roberts WL, Fang T. Spray combustion of biomass-based renewable diesel fuel using multiple injection strategy in a constant volume combustion chamber. Fuel. 2016;181:718-728.

[6] Mladenovi M, Paprika M, Marinkovi A. Denitri fication techniques for biomass combustion. Renewable and Sustainable Energy Reviews. 2017;82:1038-1046.

[7] Sansaniwal SK, Pal K, Rosen MA, Tyagi SK. Recent advances in the development of biomass gasification technology: a comprehensive review. Renewable and Sustainable Energy Reviews. 2017;72:363-384.

[8] Xingang Z, Zhongfu T,Pingkuo L. Development goal of $30 \mathrm{GW}$ for China's biomass power generation. Renewable and Sustainable Energy Reviews. 2013;25:10-17.

[9] Molino A, Chianese S, Musmarra D. Biomass gasification technology: the state of the art overview. Journal of Energy Chemistry. 2016;25:10-25.

[10] Karatas H, Olgun H, Akgun F. Experimental results of gasification of cotton stalk and hazelnut shell in a bubbling fluidized bed gasifier under air and steam atmospheres. Fuel. 2013;112:494-501.

[11] Bartela L, Kotowicz J, Jurgas DK. Investment risk for biomass integrated gasification combined heat and power unit with an internal combustion engine and a Stirling engine. Energy. 2018;150:601-616.

[12] Garami A, Csordas, Palotas A, Toth P. Reaction zone monitoring in biomass combustion. Control Engineering Practice. 2018;74:95-106.

[13] Foster E, Contestabile M, Blazquez J, Manzano B, Workman M, Shah N. The unstudied barriers to widespread renewable energy deployment : Fossil fuel price responses. Energy Policy. 2017; 103:258-264.

[14] Achawangkul Y, Maruyama N, Hirota M, Chaichana C, Sedpho S, Sutabutr T. Evaluation on environmental impact from the utilization of fossil fuel, electricity and biomass producer gas in the double-chambered crematories. Journal of 
Cleaner Production. 2015;5:308-316.

[15] Zeng T, Weller N, Pollex A, Lenz V. Blended biomass pellets as fuel for small scale combustion appliances: Influence on gaseous and total particulate matter emissions and applicability of fuel indices. Fuel. 2016;184:689-708.

[16] Eichner, Thomas RP. Trade in fossil fuel deposits for preservation and strategic action. Journal of Public Economics 2017;147:50-61.

[17] Bhaskar K, Sendilvelan S. Experimental studies on the performance and emission characteristics of a compression ignition engine fuelled with jatropha oil methyl ester. Journal of Mechanical Engineering and Sciences (JMES). 2018;12(1):34313450.

[18] Azaini NN, Masngut N. Oscillatory flow reactor design for biological process.Journal of Mechanical Engineering and Sciences (JMES) 2017; 11(2): 2615-2625.

[19] Brahma B, Jyoti A, Sileshi GW, Kumar A. Estimating biomass stocks and potential loss of biomass carbon through clear-felling of rubber plantations. Journal Biomass and Bioenergy. 2018;115:88-96.

[20] Welfe A, Gilbert P, Thornley P, Increasing biomass resource availability through supply chain analysis. Journal Biomass Bioenergy. 2014;70:249-266.

[21] Mattonai AM, Licursi D, Maria A, Galletti R, Ribechini E. Py-Gc/Ms And HplcDad Characterization Of Hazelnut Shell And Cuticle: Insights into possible reevaluation of waste biomass. Journal Analytical Applied Pyrolysis. 2017;17:1-21.

[22] Licursi D, Antonetti C, Fulignati S, Vitolo S, Puccini M. In-depth characterization of valuable char obtained from hydrothermal conversion of hazelnut shells to levulinic acid. Bioresource Technology. 2017;244:880-888.

[23] Ozyuguran A, Yaman S. Prediction of calorific value of biomass from proximate analysis. International Conference on Energy and Environment Research, Barcelona, Spain. Energy Procedia. 2017;107:130-136.

[24] Ashman JM, Jones JM, Williams A. Some characteristics of the self-heating of the large scale storage of biomass. Fuel Processing Technology. 2018;174:1-8.

[25] Abuelnuor AAA, Wahid MA, Ehsan S. Characteristics of biomass in flameless combustion. Renewable and Sustainable Energy Reviews. 2014;33:363-370.

[26] Li J, Paul MC, Younger PL, Watson I, Hossain M, Welch S. Characterization of biomass combustion at high temperatures based on an upgraded single particle model. Applied Energy. 2015;156:749-755.

[27] Kraszkiewicz A, Przywara A, Kachel JM, Lorencowicz E. Combustion of plant biomass pellets on the grate of a low power boiler. Agriculture and Agricultural Science Procedia. 2015;7:131-138.

[28] Hrdlicka J, Skopec P, Tomas DFH. Emission factors of gaseous pollutants from small scale combustion of biofuels. Fuel. 2016;165:68-74.

[29] Deng L, Torres RD, Burford M, Lehmann J, Fisher EM, Whitlow TH. Fuel sensitivity of biomass cookstove performance. Applied Energy. 2018;215:13-20.

[30] Orhorhoro EK, Chukudi OM and Onogbotsere ME. Design and fabrication of an improved low cost biomass briquetting machine suitable for use in Nigeria. International Journal Of Engineering Technology And Sciences (IJETS). 2017;8(1):1-11.

[31] Rodrigo C, Lima R, Manoel F, Nogueira M, Danielle R, Guerra S. CFD modeling of a small-scale cyclonic combustor chamber using biomass powder. INFUB - 11 th European International Conference on Industrial Furnaces and Boilers. Energy Procedia. 2017;120:556-563. 
[32] Guo F, Zhong Z. Experimental studies on combustion of composite biomass pellets in fluidized bed. Journal Science of the Total Environment. 2017;599600:926-933.

[33] Deng L, Ye J, Jin X, Zhu T, Che D. Release and transformation of potassium during combustion of biomass. International Conference on Applied Energy, UK. Energy Procedia. 2017;142:401-406.

[34] Ozyuguran A, Akturk, Yaman. Optimal use of condensed parameters of ultimate analysis to predict the calori fi c value of biomass. Fuel. 2018;214:640-646.

[35] Jiang T, Hon L, Kamal M, Aziz A, Azian N. Enhanced biomass characteristics index in palm biomass calorific value estimation. Applied Thermal Engineering. 2016;7(2):527-534.

[36] Cao W, Li J, Lue L. Study on the ignition behavior and kinetics of combustion biomass.International Conference on Applied Energy, UK. Energy Procedia. 2017;142:136-141.

[37] Strzalka R, Erhart TG, Eicker U. Analysis and optimization of a cogeneration system based on biomass combustion. Applied Thermal Engineering. 2013;50(2):1418-1426.

[38] Al-Kayiem HH, and Yunus MY. Drying of empty fruit bunches as wasted biomass by hybrid solar- thermal drying technique. Journal of Mechanical Engineering and Sciences (JMES). 2013;5:652-661.

[39] Ahmad R, N. Hamidin UFMA and CZAA. Characterization of bio-oil from palm kernel shell pyrolysis. Journal of Mechanical Engineering and Sciences (JMES). 2014;7:1134-1140.

[40] Swamy MK, Patchouli ( Pogostemon cablin Benth): Botany, agrotechnology and biotechnological aspects. Industrial Crops and Products. 2016;87:161-176.

[41] Masiren EE, Harun WHW, Ibrahim FA. Effect of temperature on diffusivity of monoethanolamine on absorption process for $\mathrm{CO}_{2}$ capture. International Journal Of Engineering Technology And Sciences. 2015;3:1-6.

[42] Ali S, Mehrabian R, Hochenauer C, Scharler R. The virtual biomass grate furnacean overall CFD model for biomass combustion plants biomass combustion plants.INFUB - 11th European International Conference on Industrial Furnaces and Boilers,. Energy Procedia. 2017;120:516-523.

[43] Hardyanti IS, Nurkhalisa S, Maghfiroh H. Comparison of bentonite and zeolite as adsorbent purification process of patchouli oil ( Pogostemon cablin ).Journal of Scientific and Innovative Research. 2017;6:87-90.

[44] Norrizam Jaat, Amir Khalid, Adiba Rhaodah Andsaler, Azwan Sapit AR and MB. Effects of ambient temperature and injection pressure on biodiesel ignition delay. Journal of Mechanical Engineering and Sciences. 2017;11:2723-2733.

[45] Damodara D Reddy, Makena Harish MAR. Thermoelectric power generation from biomass cook stove : a waste heat to energy conversion. International Journal Of Engineering Technology And Sciences (IJETS). 2014;2(1):43-47.

[46] Ullah A, Jamil I, Gillani. Investigation on hydrodynamics of gas fluidized bed with bubble size distribution using energy minimization multi scale mixture model. Journal of Mechanical Engineering and Sciences. 2018;12(1):3451-3460.

[47] Banu SF, Rubini D, Shanmugavelan P. Effects of patchouli and cinnamon essential oils on biofilm and hyphae formation by Candida species. Journal of Mycologie Medicale.2018:8-15. 